\title{
JOURNAL.RU
}

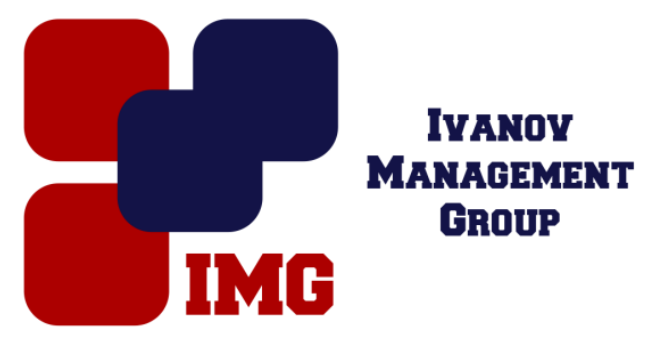

Алимжанов А.Е.

ФГКОУ ВО «Омская академия Министерства внутренних дел Российской Федераџии»

Омск, Россия

doi: $10.18411 / \mathrm{lj}-30-06-2017-39$

idsp 000001:1j-30-06-2017-39

\section{Сохранение физической активности государственных служащих в непрерывном профессиональном образовании}

\section{Аннотация}

В статье сохранение физической активности государственных служащих рассматривается как педагогическая задача, которая встраивается в процесс их самостоятельного непрерывного профессионального образования. Раскрыты организационно-педагогические условия успешности сохранения физической активности государственных служащих в процесс непрерывного профессионального образования.

Ключевые слова: физическая активность государственных служащих, сохранение физической активности, непрерывное профессиональное образование.

Эффективность профессиональной деятельности государственных служащих в значительной степени определяется уровнем их физической активности, которая целенаправленно и специально задается в основном в системе профессионального образования (физическая культура, физическая подготовка, соревновательная деятельность и пр.), а затем поддерживается и развивается государственными служащими самостоятельно. Проблема сохранения физической активности государственных служащих возникает в связи с тем, что далеко не все виды профессиональной деятельности государственной службы предполагают постоянное физическое напряжение, физическую нагрузку. Объективными факторами снижения физической 
активности являются: «кабинетная» работа и гиподинамия; служебная нагрузка и напряженный режим профессиональной деятельности, препятствующий регулярным занятиям спортом и физической культурой; повышение возраста и возрастные изменения здоровья, слабая медицинская активность; нарушение режима труда и отдыха; нездоровый образ жизни и вредные привычки и др.

Вместе с тем, снижение физической активности государственных служащих характеризуется и субъективными факторами, среди которых:

- несоответствие уровня знаний и представлений о роли физической активности в профессиональной деятельности актуальной ситуации профессионального развития специалиста (занимаемой должности, перспективам профессионального роста, характеру текущей и возможной профессиональной деятельности, возрасту, состоянию здоровья и пр.);

- отсутствие новых навыков, требуемых для сохранения физической активности на уровне, обеспечивающем нормальное самочувствие, работоспособность и эффективность выполнения профессиональных задач, пренебрежение занятиями физической культурой и спортом;

- восприятие физической культуры и спорта как внешнее требование, элемент контроля, а не как внутреннюю потребность человека, определяемую его активностью в целом.

Сочетание субъективных и объективных факторов делает сохранение физической активности государственных служащих педагогической задачей. В педагогическом смысле сохранение физической активности государственных служащих представляется нам как своевременное оснащение государственного служащего знаниями, умениями и опытом, актуализация соответствующей мотивации, а также развитие качеств, необходимых для сознательного, обоснованного, мотивированного выбора и удержания государственным служащим такого режима физической нагрузки, который обеспечивает его трудоспособность, поддержание здоровья и самочувствия, возможность выполнить потенциальные профессиональные задачи, характеризующиеся повышенным физическим и психическим напряжением. Выступая педагогической задачей, сохранение физической активности государственных служащих встраивается в процесс их самостоятельного непрерывного профессионального образования, связанного с самоизменением личности, сознательным «выходом» на новый уровень планирования и управления своей 
жизнью. По мнению О. Е. Шафрановой, оно возможно там, где ценностью для человека становится не только результат, но и сам процесс образования [1].

Непрерывное профессиональное образование несет в себе элемент организованности и системности в силу заинтересованности в его эффективности конкретных субъектов: работодателей, ведомств, а в случае с государственными служащими - государства и общества. Существует вполне определенный социальный заказ непрерывному профессиональному образованию, который в системе государственной службы РФ выражен ведомственными нормативными актами о подготовке кадров и квалификационными требованиями к должностям государственной службы (государственный заказ); общественным мнением и научными разработками (социальная часть); профессиональными нормами и традициями (корпоративная, социально-профессиональная часть); личными потребностями человека в здоровье, работоспособности и профессиональной самореализации (личностный заказ).

Проблема сохранения физической активности государственных служащих имеет эшелонированный характер, еe постановка зависит от вида государственной службы. Не выражена она в государственной военной службе (Вооруженные Силы и Национальная Гвардия РФ, другие аналогичные по профилю деятельности виды государственной службы), поскольку высокий уровень физического развития (и, соответственно, физической активности) является обязательным квалификационным требованием к военнослужащим, а физическая подготовка и спорт составляют обязательную часть военнопрофессиональной деятельности. $\mathrm{K}$ этой же категории можно отнести оперативные структуры иных видов государственной (не военной) службы. Физическая активность здесь рассматривается в связи с установленными профессиональными требованиями к сотрудникам, а выполнение ими профессиональных задач требует развитых физических качеств, которые формируются и поддерживаются в рамках специальных занятий по физической подготовке. Однако в ряде работ даже на этом уровне уже прослеживается актуальная проблема мотивации и самостоятельности сотрудников, которая возникает при изменении условий их профессиональной деятельности [2].

Иной уровень актуализации проблемы сохранения физической активности характерен для сотрудников иных видов государственной службы, не занимающихся оперативной работой, но попадающих под требования руководящих документов к физической подготовке. Так, например, 
Е. В. Князева, классифицируя профессиональные задачи сотрудников правоохранительных органов по запросам к физической подготовке, выделяет группу сотрудников, деятельность которых носит «...камеральный, административно-канцелярский (кадровая и воспитательная работа, паспортновизовая служба, лицензионно-разрешительная работа и др.) характер» [3]. Аналогичные виды профессиональной деятельности, не связанные с постоянными физическими нагрузками, существуют в таких видах государственной службы, как прокуратура, служба исполнения наказаний, таможенная служба и пр.

Наиболее проблемный уровень актуализации проблемы проявляется в отношении сотрудников государственной гражданской службы, где физическая активность практически не установлена в профессиональных требованиях и целиком отнесена к личной ответственности государственного служащего. Анализ современной научной литературы дает основания констатировать, что на этом самом критичном уровне проблема сохранения физической активности государственных служащих скрыта и практически не осмыслена.

Реализация педагогического пути вполне возможна в непрерывном профессиональном образовании государственного служащего при создании ряда организационно-педагогических условий:

1. Использование в организации непрерывного профессионального образования государственных служащих программно-целевого управления [4], которое предполагает постановку органами управления различных видов государственной службы самой цели сохранения физической активности государственных служащих, а также объединение усилий органов управления, образовательных организаций и образовательных подразделений для еe достижения за счет разработки и реализации педагогических программ в системе непрерывного профессионального образования.

2. Ресурсное обеспечение поддержки физической активности государственных служащих. Ее полное ресурсное обеспечение возможно при объединении административного, нормотворческого и информационного ресурсов органов управления видами государственной службы, научнометодического и образовательного ресурсов организаций образования или ведомственных образовательных подразделений, материально-технического и кадрового ресурсов системы физической культуры и спорта. 
3. Глубокая индивидуализация и дифференциация педагогического взаимодействия с государственными служащими, сочетание организованных и самостоятельных занятий физической культурой и спортом.

Анализ основных концепций и теорий непрерывного профессионального образования в РФ свидетельствует о том, что в системе непрерывного профессионального образования возможна и обладает потенциальной эффективностью педагогическая поддержка физической активности государственных служащих. Это объясняется тем, что непрерывное профессиональное образование представляет собой организованное извне и управляемое пространство личностного развития субъекта профессионального труда, где через образовательные проекты возможно влияние на весь комплекс профессионально важных качеств личности, процессы самообразования и самостоятельного профессионального развития [5].

Непрерывное профессиональное образование государственных служащих имеет организованный, цикличный и частично управляемый характер [6], что позволяет ставить и решать долгосрочные задачи не только в образовательных проектах (в системе повышения квалификации, в профессиональнодолжностной подготовке), но и в довольно длительные периоды между ними (в самообразовании и самостоятельном профессиональном развитии, в дополнительном общем образовании и пр.). Организация непрерывного профессионального образования государственных служащих четко регламентирована федеральными законами о видах государственной службы, ведомственными нормативными актами, квалификационными требованиями к государственным служащим. Его ступенчатый, постоянно усложняющийся характер позволяет формировать уровневую педагогическую поддержку физической активности государственных служащих, содержание, формы и методы которой изменяются в соответствии с возрастом, состоянием здоровья и потребностями обучающихся.

Наконец, система непрерывного образования государственных служащих строится преимущественно кластерным методом, обеспечивающим особый способ взаимодействия организаций государственной службы и образовательных организаций. В сохранении физической активности служащих кластеры фактически составляют единое целое, преследуют общие интересы и получают права на использование совместных образовательных ресурсов. Такая связь делает принципиально возможной педагогическую поддержку физической 
активности государственных служащих в непрерывном профессиональном образовании.

Наиболее значимую роль в решении поставленной задачи играет активная часть непрерывного профессионального образования - система дополнительного профессионального образования, объединяющая различные формы целенаправленного и организованного педагогического взаимодействия с государственными служащими в процессе реализации дополнительных профессиональных программ (повышение квалификации, профессиональная переподготовка, стажировка и т. д.), обеспечивающих получение новых или повышение уровня имеющихся профессиональных компетенций, повышение профессиональной квалификации.

Таким образом, сохранение физической активности государственных служащих есть комплексная профессиональная проблема, для решения которой существуют и педагогические пути. При условии, что сохранение физической активности государственного служащего сочетает в себе личные, государственные и общественные потребности, признается всеми субъектами образовательной системы, дополнительное профессиональное образование может быть точкой приложения основных педагогических усилий в решении заявленной проблемы. Однако в вопросах сохранения физической активности государственных служащих, которое следует рассматривать как непрерывный процесс, большое значение приобретает межкурсовой период, где непрерывное профессиональное образование, несмотря на наличие активных форм педагогического взаимодействия (обучающие семинары, обмен опытом, занятия профессионально-должностной подготовки и пр.), имеет самостоятельный характер. 
1. Шафранова О. Е. Аксиология непрерывного образования преподавателя высшей школы: монография. - Биробиджан: ГОУ ВПО «ДВГСГА», 2011. - 271 с.

2. Шаповалов С. В. Методика физической подготовки оперативных сотрудников Федеральной службы Российской Федерации по контролю за оборотом наркотиков: дис. ...канд. пед. наук. - Хабаровск, 2012. - 224 с.

3. Князева Е. В. Физическая подготовка сотрудников ОВД, выполняющих работу камерального профиля: дис. ...канд. пед. наук. - СПб., 2003. - 138 с.

4. Близневский А. Ю. Программно-целевое управление развитием сферы физической культуры и спорта в пространстве Красноярского края: дис. ...д-ра пед. наук. - СПб., 2015. $-381 \mathrm{c}$.

5. Александров А. А. Вопросы теории и реализации непрерывного образования: монография. - М.: Изд-во МГОУ, 2012. - 270 с.

6. Ерегина А. Г. Дополнительное профессиональное образование как фактор профессионального развития государственных гражданских служащих: автореф. дис. ...канд. социол. наук. - М., 2015. - 28 с. 